\title{
Hacer las paces, desafio de la nueva sociedad
}

\author{
Mauricio Castro Martínez*
}

\section{Resumen}

El principal propósito de este documento es reflexionar acerca de los estudios contemporáneos sobre la construcción de paz. En primera medida, para llamar la atención sobre la complejidad de transitar del paradigma de la violencia hacia nuevas mentalidades que versen sobre el paradigma de la paz, a partir de la interpretación de un marco conceptual más amplio. Segundo, para hablar de hacer las paces, reconocer la necesidad de respetar las diferencias como parte del sustrato social y otorgar valor a la relación de igual-diferente que enmarca a las nuevas realidades en escenarios de no violencia.

Palabras clave: cambio social, construcción de paz, diálogo, no violencia

\section{Abstract}

This paper aims to reflect about contemporary studies on peacebuilding. First, to call attention to the complexity of moving from the paradigm of violence towards new mentalities that deal with the paradigm of peace, while interpreting it from a broader conceptual framework. Secondly, there is talk of making peace, recognizing the need to respect differences as part of the social substrate and giving value to the equal - different relationship, that frames the new realities in nonviolent scenarios.

Keywords: dialogue, nonviolence, peace building, social change

* Comunicador Social - Periodista, especialista en Protección comunitaria y magíster en Cultura de Paz, Conflictos, Educación y Derechos Humanos. Docente de la Corporación Unificada Nacional de Educación Superior, Regional Tolima. Contacto: edwin_castrom@cun.edu.co 


\section{Introducción}

El recorrido histórico de la humanidad se ha contado, principalmente, desde una perspectiva violenta. Esa es la tendencia antropológica que ha determinado la relevancia de los hechos y ha trascendido, además, en factores como el lenguaje y las costumbres, razón por la que es común encontrar relatos que dan cuenta de la fortaleza de los pueblos desde su poder bélico o de sus victorias en el campo de batalla. Por ejemplo, bajo la premisa de 'quien quiera la paz, que se prepare para la guerra' (si vis pacen, para bellum), los romanos definieron sus figuras de poder desde lo militar, lo que generó fricciones dentro del aparato social, pues para algunos lo político era secundario o aún un poder paralelo. Así, la pax romana comprendía un sistema de orden y control; había una aparente ausencia de violencia, pero no se garantizaban condiciones de prosperidad y justicia (Jiménez, 2009).

En consecuencia, las sociedades se tejieron alrededor de esa 'realidad de la guerra' y entendieron la paz como un pasaje transitorio en medio de sus avances y retrocesos. Esa fascinación por el conflicto y sus manifestaciones violentas, que comenta Lederach (2007, p. 31), marcaron la pauta en la comunidad académica que durante el siglo xx se dedicó a estudiar la guerra, sus dinámicas y consecuencias.

Desde esta mirada, los conflictos han sido una circunstancia protagónica en el desarrollo de los pueblos, pues en torno a ellos se ha dado la caída de imperios y han surgido nuevos estados independientes, como lo relata, por ejemplo, la historia de las naciones latinoamericanas.
Entonces, concebir la paz desde una dimensión negativa, afirmándola únicamente como la ausencia de la guerra - en el sentido de Galtung (2003) - , nos devuelve al paradigma de la pax romana, tendencia que permanece hasta finales de la Segunda Guerra Mundial, momento en el que se comienza a gestar un giro epistemológico que asume la paz como eje fundamental de estudio y se tratan de rescatar planteamientos y prácticas posteriores, que hasta ese momento estuvieron aisladas.

Así, en la década de los años 50, el Manchester College of Indiana en Estados Unidos, presenta la primera escuela de estudios para la paz, además del Instituto de Investigación para la Paz, que funda Johan Galtung en Noruega y el Instituto Internacional de Investigación para la Paz, en Estocolmo, impulsado por el gobierno sueco.

Sin embargo, solo a partir de los años 90 los estudios para la paz ${ }^{1}$ toman una nueva dinámica a propósito de los aportes de Dogan y Pahre (1993), que se refieren a la fase i) fundacional, ii) de expansión, iii) especialización $y$, iv) de hibridación de la paz, que se complementan con estudios posteriores en los que se plantea la necesidad de satisfacer las demandas de las personas y el respeto por sus derechos fundamentales, ya que las falencias en este sentido, son el prólogo de conflictos que pueden degenerar en guerras (Jiménez, 2014; Muñoz y Martínez, 2000). Esta perspectiva imprime un nuevo ángulo de análisis sobre el paradigma de la violencia, explicada

1 Posterior a la Segunda Guerra Mundial y a los diálogos de París, se despertó especial inquietud por entender los conflictos como una herramienta preventiva para evitar nuevos episodios de violencia. A partir de ese momento, han sido varias las iniciativas que en diferentes partes del globo han impulsado la investigación y nuevas propuestas en torno a la paz. A ese movimiento científico se le conoce como investigación para la paz o peace research en el ámbito anglosajón. 
desde la triangulación entre sus causas estructurales, la transversalidad cultural (que legitima la violencia desde la ideología) y las manifesta- ciones directas que atentan contra la integridad física de las personas y la vida (Galtung, 2003).

\section{La paz como perspectiva}

En el último tercio del siglo pasado, la humanidad se vio estremecida por un nuevo episodio de conflictos armados de los que dan cuenta, entre otros, la guerra del Golfo Pérsico, el genocidio de Ruanda o el colapso de la antigua Yugoslavia, que dejaron fuertes consecuencias a nivel global. En consecuencia, en un intento por entender el estado de las cosas de una manera más completa y construir vasos comunicantes, entre los nuevos referentes teóricos de los estudios para la paz y lo que estaba sucediendo en la práctica, Knight (2003) distingue tres perspectivas: i) economía, la mayoría de los conflictos civiles se dan por problemas económicos, lo que traslada la discusión acerca del modelo de desarrollo y crecimiento económico de los países, ii) política, los conflictos violentos obedecen a raíces políticas y en consecuencia, la solución es posible en tanto se garanticen espacios de participación política, que garanticen la contienda por una vía pacífica que permita llegar a la democratización del poder $y$, iii) el desbordado poder armamentista que se intensifica en las regiones, lo que aumenta el riesgo de iniciar o intensificar los conflictos bélicos. Esto hace necesaria la implementación de procesos de desarme y desmovilización que contribuyan al mantenimiento de la paz.

Lo anterior ha motivado un giro epistemológico que aporte en los procesos de construcción, establecimiento y mantenimiento de una cultura de la paz, como lo explica Martínez (2001), "sea una cultura de prevención antes que de reacción" (p. 12).
En el libro Noviolencia. Teoría, acción politica y experiencias, Mario López (2012) señala que "las cosas pueden ser y hacerse de otra manera. Nos podemos estar equivocando (y mucho), por eso hay que rectificar, cambiar de rumbo, [...] recuperar el valor de lo humano, pues está en juego la supervivencia como especie y como planeta vivo" (p. 5). A partir de ello y en coincidencia con Martínez (2001), en el sentido de que el desafío se concentra en encontrar nuevas formas de gobernanza y de ampliar la concepción de seguridad, ya no solo a los Estados y la esfera de las relaciones internacionales y la diplomacia sino hablar y gestionar en función de la seguridad humana, que facilite los espacios de construcción de paz desde la atención a necesidades humanitarias, al tiempo que facilite espacios para la construcción de la paz y el tránsito al postconflicto, incluidos - como ya se mencionó-, el desarme, la desmovilización y, quizá el punto más relevante, la reintegración de antiguos soldados (regulares e irregulares) a la vida civil, con un eventual auxilio económico que les facilite iniciar proyectos de vida sostenibles.

Esto llama la atención en tanto que, si la violencia ha sido protagonista durante siglos, no es tarde para replantear la paz, desde la humanización de las nuevas realidades, como el eje que proyecte las sociedades y sus ciudadanos. Así, en virtud de la tendencia globalizadora y cercano a lo que Kant acuñó, en su obra Sobre la paz perpetua (2012) como la idea de una república mundial, esta idea no debe limitarse a la imposición de leyes coactivas; sino 
trascender a la formulación de nuevas políticas de estado, que fomenten la preservación de la paz y enfrenten los retos y crisis de la edad moderna con soluciones incluyentes.

Lo anterior busca dirimir la tensión entre la restricción de libertades y abrir el diálogo acerca de la garantía de derechos, y de este modo abrir el espacio a nuevas interpretaciones, como el fenómeno de la migración, que siempre ha estado vigente.

Ahora bien, es necesario coincidir en que la paz y la violencia seguirán estando relacionadas, no solo en su definición conceptual, sino además en sus dinámicas, toda vez que la primera apunta a disminuir el grado de belicismo al tiempo que contrarresta las causas estructurales de la violencia para reducir sus efectos. Esto constituye el horizonte vital de la sociedad - en el sentido de Pachón (2010) - y propone la paz desde un viraje cultural que la desplaza del abismo de lo utópico hacia la dimensión de lo posible.

A esta evolución del paradigma, Jiménez la refiere como la hibridación o amalgama antropológica, que distingue la paz como una máxima que "todo el mundo reconoce; pero que pocos pueden definir satisfactoriamente" (2014, p. 27), y que exige avanzar en la construcción de consensos multidisciplinares que vayan más allá de los límites epistémicos que buscan diferenciar una disciplina de la otra. La otredad es uno de los factores que emerge y se suma en el proceso de consolidar un cambio cultural que reconozca las diferencias en una sociedad de iguales-diferentes. Este giro axiológico destaca la importancia que trasciende una mera distinción lingüística de género, raza, edad o creencias.

Se debe reflexionar no solo sobre las mayorías en la sociedad y sus relaciones de poder (Foucault, 1988), sino acerca del lugar y protagonismo que las minorías han tenido a lo largo de la historia y su riqueza cultural. Preocupa, por ejemplo, el caso de las comunidades indígenas que aún hoy siguen siendo relegadas a la invisibilidad de un inframundo en el que algunas mayorías las han querido confinar, al ignorar su derecho histórico y negando a la sociedad la posibilidad de lo que Llull llamaba el diálogo indispensable (citado en Mayer, 2010), que brinda la oportunidad de reivindicar su pasado y construir hacia la paz. La crisis de los pueblos indígenas se complica aún más, en tanto los estados insisten en imponer legislación y costumbres a estos grupos, lo que se constituye una recolonización de sus tradiciones.

Lo mismo pasa con los idearios de igualdad de género o la libertad de credo, que hacen caer en cuenta acerca de la masculinidad y occidentalización que se le ha dado al conocimiento, a las ciencias y en muchos casos, a las investigaciones.

\section{La propuesta del diálogo}

La construcción de una cultura de paz, como lo explica Toro (2015), debe volver la mirada hacia la fortaleza de dialogar, ya que en esto reside la capacidad de deconstruir la violencia que parece haberse naturalizado en la cotidianidad de las sociedades y dar cabida a seguir motivando escenarios de respeto y reconocimiento por la existencia del otro. Esto sugiere la articulación de saberes y capacidades de las personas en espacios participativos, que faciliten la construcción 
colectiva de decisiones que afecten al colectivo social, acaben con las diferentes formas de discriminación y reconozcan la diversidad cultural. Todo lo anterior, redunda en avances para la reconstitución del tejido social y fortalece el ejercicio democrático, al tiempo que obliga a reflexionar y ajustar los modelos de gobernanza.

Jiménez (2014) define el diálogo como el vehículo para alcanzar la hibridación y los mestizajes, propios de la neutralidad como un escenario que permite responder de manera positiva a las nuevas formas de violencia, y que en consecuencia exige la deconstrucción de cosmovisiones, que en sus palabras impiden la adquisición de nuevos modelos. Por su parte Vincent Martínez (2001) debate acerca de la filosofía discursiva, y plantea que decirnos cosas, es hacernos cosas y cómo la palabra se configura en una herramienta clave para naturalizar la paz dentro de la cotidianidad.

las paces, validando diferentes posturas de mediación, análisis y dinámicas que pertenecen al contexto desde el que se estudian, dando una característica aséptica y libre de prejuicios ideológicos, que no perturben, sino que aporten, a la resolución de los conflictos y la reconstitución del tejido social.

Trabajar por la paz supone entonces un ejercicio continuo, basado en la inquietud científica, en la propuesta de giros epistemológicos que faciliten rescatar los valores y en consecuencia resignificar al hombre en sus realidades y, desde estas, proponer conceptos y materializarlos en prácticas que marquen la corresponsabilidad del Estado y la sociedad respecto a la cultura de paz. Así, a riesgo de ser catalogado como idealista, quien cree en la paz como un eje axial de la sociedad, debe aportar con la coherencia, no solo desde lo académico, sino desde lo vivencial. Recomponer el aparato social no es una tarea que se cristalice desde la sátira y la crítica aislada.
Si se retoma el concepto de otredad, se legitima y reconoce al otro como sujeto de derechos; por consiguiente, no se puede hablar de una sola paz, impuesta y definida de manera categórica. Toma importancia hablar una vez más de 
Es necesario ser propositivo y elocuente, acorde al rol que se ocupa en la sociedad; se debe entender que no hay acciones pequeñas: todas las dinámicas que alimentan la cotidianidad son una cadena comportamental que en el corto, mediano y largo plazo tendrán un efecto coyuntural que modificará las bases del sistema.

Desde esta óptica, es menester de la cultura de paz educar para el cambio, ya que los constantes conflictos son prueba de que las estrategias empleadas no han sido efectivas. Si así lo fueran, la guerra, que es una forma de violencia directa, no seguiría siendo protagónica. En consonancia con esta línea, es necesario materializar iniciativas que propendan por nuevas metodologías de enseñanza y pautas de comportamiento que otorguen nuevas maneras de hacer frente a los grandes problemas sociales que la posmodernidad plantea, todos ellos, entretejidos en una complejidad estructural que requiere nuevas propuestas de paz (Fisas, 1994).

Igualmente, es necesario redefinir el asunto de la seguridad y la defensa, desmilitarizar el imaginario colectivo, el ejercicio de la política y, en consecuencia, despojar de un tinte militarista a las políticas de Estado que conciben la fuerza como la única y mejor vía de garantizar su cumplimiento. El uso obcecado de la fuerza, cobijado por una constitucionalidad oportunista, fractura el carácter democrático de las sociedades $y$ es semillero de nuevos escenarios que violentan al hombre y sus libertades, y dan paso a las crisis que dejan los escombros de estados fallidos. Vale la pena mencionar el concepto de López (2012), en el que se aclara que la historia de la paz es también una historia de la violencia, y que aportar a la construcción social es poner sobre la mesa una nueva mirada, contar para desaprender la guerra, pero no para olvidarla, es describir desde las perspectivas de las víctimas, no solo es una historia que comienza cuando la guerra termina, sino que es una historia de lo que queremos que sea y que signifique la paz.

Cabe contrastar que el relativismo sin fundamento puede ser también fatal. La cultura de paz no puede tratarse de ensanchar las márgenes del imaginario colectivo, a fuerza de abarcar a todos y todo. Es decir, que, se deben plantear unos mínimos básicos, como quiera que el orden social se deba establecer. Si acaso se entendiera la paz como el reinado de la anarquía, luego, a fuerza de imponer este nuevo modelo, se caería en una nueva práctica violenta. No sería probo que en aras de entender o practicar la paz se caiga en una dimensión negativa, conformista y paralizante del ser humano (Muñoz, Herrera, Molina y Sánchez, 2005).

Por último, es importante anotar que la construcción de una cultura de paz es un ejercicio inacabado, imperfectivo si se quiere (Muñoz y Martínez, 2000), ya que las dinámicas sociales y las relaciones humanas son cambiantes y se dan en tanto el contexto lo determina y en ese mismo ritmo deben avanzar los estudios y prácticas pacifistas.

En cualquier caso, se deben afirmar e innovar las acciones no violentas. Hacer la paz, o las paces, no se da desde un estado pasivo del hombre, por el contrario exige acción y palabra en alto grado de compromiso. En torno a esta idea aparece la figura del perdón, un componente importante en la reconstrucción del tejido social.

A partir del carácter activo de la paz, el perdón debe entonces entenderse como una acción 
que permite dar comienzo a nuevas etapas de la existencia humana. Puesto que es imposible cambiar la condición irreversible del pasado, se debe, entonces, tejer redes de respeto y diálogo que hagan transitable el camino de la paz para las generaciones vigentes y futuras en las proporciones justas a cada contexto.

La posible redención del predicamento de irreversibilidad -de ser incapaz de deshacer lo hecho aunque no se supiera, ni pudiera saberse, lo que se estaba haciendo- es la facultad de perdonar. El remedio de la imposibilidad de predecir, de la caótica inseguridad del futuro, se halla en la facultad de hacer y mantener las promesas. (Arendt, 1993, p. 255)
No es posible perdonar desde la mentira o la impunidad. Se perdona desde la justicia, que debe propender por la resocialización del ser humano y la reconstrucción de la verdad, no solo con fines jurídicos, sino con propósitos históricos. Se destacan elementos como las comisiones de la verdad, que, en un escenario de conflicto, por ejemplo, sin el interés de ostentar poder judicial, buscan rescatar la memoria de las víctimas desde el contraste de testimonios que permitan esclarecer episodios de violencia. Con el propósito de reducir la espiral de la violencia, la acción de perdonar va entrelazada con la verdad; pero la verdad debe contarse desde todas las miradas, escuchada por el conjunto de la sociedad, siendo esta la más básica de las acciones no violentas, y contrastarse en un ejercicio de reconciliación social. 


\section{Referencias}

Arendt, H. (1993). La condición humana. Barcelona: Paidós.

Dogan, M. y Pahre, R. (1993). Las nuevas ciencias sociales: la marginalidad creadora. México D. F.: Grijalbo.

Fisas, V. (1994). Alternativas de defensa y cultura de paz. Madrid: Fundamentos.

Foucault, M. (1988). El sujeto y el poder. Revista Mexicana de Sociología, 50(3), 3-20.

Galtung, J. (2003). Paz por medios pacíficos. Paz y conflicto, desarrollo y civilización. Bilbao: Bakeas.

Jiménez, F. (2009). Saber pacifico: la paz neutra. 'Marco para una agenda de estudios para la paz y los conflictos'. Loja: UTP.

Jiménez, F. (2014). Paz neutra: una ilustración del concepto. Revista de Paz y Conflictos, 7, 19-52. Recuperado de https:// bit.ly/2uqkrzD

Kant, I. (2012). Sobre la paz perpetua. Madrid: Akal.

Knight, W. (2003). Evaluating recent trends in peacebuilding research. International Relations of the Asia-Pacific, 3(2), 241-264. Dor: https:// doi.org/10.1093/irap/3.2.241

Lederach, J. (2007). La imaginación moral. El arte y el alma de la construcción de la paz. Bilbao: Gernika-Lumo, Bakeaz.

López, M. (2012). Noviolencia. Teoría, acción política y experiencias. Granada: Educatori.

Martínez, V. (2001). Filosofía para hacer las paces. Barcelona: Icaria.

Mayer, A. (2010). Ramon Llull y el diálogo indispensable. Quaderns de la Mediterrània, 14, 231-232. 
Muñoz, F. y Martínez, M. (Eds.). (2000). Historia de la Paz. Tiempos, espacios y actores, Granada: Instituto de la Paz y los Conflictos. España: Universidad de Granada.

Muñoz, F., Herrera, J., Molina, B. y Sánchez, S. (2005). Investigación de la paz y los derechos humanos desde Andalucía. Granada: Universidad de Granada. Recuperado de https:// bit.ly/37pnRQw

Pachón, D. (2010). Una mirada crítica al Vitalismo Cósmico de Darío Botero Uribe. Pensamiento Jurídico, 28, 321-351.

Toro, G. (2015). Aproximación a un modelo de comunicación para el desarrollo y la paz en contextos vulnerables. Estudios Políticos, 46, 125-146. 